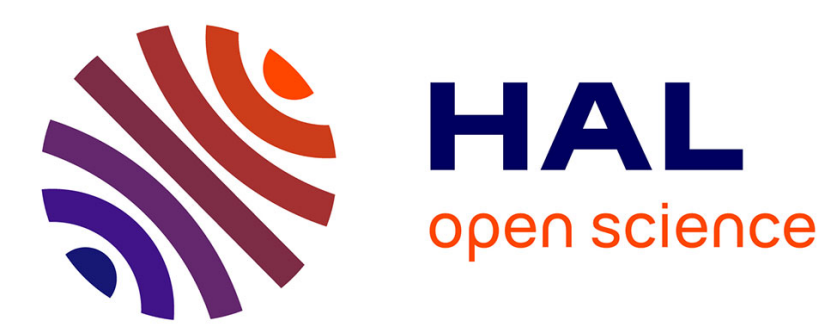

\title{
A robust total compensation algorithm for the torque control of a synchronous servomotor
}

Bruno Le Pioufle, G. Georgiou, J.-P. Louis

\section{To cite this version:}

Bruno Le Pioufle, G. Georgiou, J.-P. Louis. A robust total compensation algorithm for the torque control of a synchronous servomotor. Journal de Physique III, 1992, 2 (1), pp.129-144. 10.1051/jp3:1992115 . jpa-00248724

\section{HAL Id: jpa-00248724 https://hal.science/jpa-00248724}

Submitted on 1 Jan 1992

HAL is a multi-disciplinary open access archive for the deposit and dissemination of scientific research documents, whether they are published or not. The documents may come from teaching and research institutions in France or abroad, or from public or private research centers.
L'archive ouverte pluridisciplinaire HAL, est destinée au dépôt et à la diffusion de documents scientifiques de niveau recherche, publiés ou non, émanant des établissements d'enseignement et de recherche français ou étrangers, des laboratoires publics ou privés. 


\title{
A robust total compensation algorithm for the torque control of a synchronous servomotor
}

\author{
B. Le Pioufle $\left(^{1}\right)$, G. Georgiou $\left({ }^{2}\right)$ and J.-P. Louis $\left({ }^{1}\right)$ \\ (1) Laboratoire d'Electricité, Signaux et Robotique CNRS/LESIR, ENS de Cachan, 61 av. du Pt. \\ Wilson, 94230 Cachan, France \\ (2) Laboratoire des Signaux et Systèmes CNRS/ESE, Plateau du Moulon, 91192 Gif-sur-Yvette, \\ France
}

(Received 11 April 1991, revised 2 September 1991, accepted 20 September 1991)

\begin{abstract}
In this paper, we present a performing torque controller for a synchronous servomotor. As we will see, this controller, called the total compensation controller, brings a new solution to the defects of the well known proportional integral controller in the D-Q frame, omnipresent in industrial applications. Here, we propose a comparative study of these two algorithms, the main problem of the proportional integral controller in the D-Q frame being its high sensitivity to the speed's dynamics. We show that the total compensation controller resolves this problem. Nevertheless, the total compensation controller algorithm requires a measurement of the mechanical speed. Thus, we had to test its robustness with respect to an imprecise measurement of the motor velocity. As we will see, this controller is not robust enough. In order to improve this robustness, we propose a solution: the total compensation controller with integrators. This last controller, which has been implemented with a broadly diffused microprocessor (Intel 8086), presents convincing features : a fast torque response time for any dynamics of the mechanical speed, with a very good robustness.
\end{abstract}

\section{Introduction.}

Synchronous servomotors are being used more and more in industrial applications where they succeed to the direct current motor [1]. They have better performances (for instance the torque/mass ratio) and do not have any mechanical commutator (this commutator poses a real problem for its maintenance, especially when it is used in a corrosive environment).

On the other hand, the synchronous servomotor is more demanding. The commutator function is synthesized from an electronic set (a power inverter and a rotor position captor) [24].

Classical speed regulations use the successive loops control, the internal loop being the torque regulation and the external one the speed regulation. Thus, a standard approximation is made, considering that the dynamics of the speed is slow compared to the dynamics of the currents, so that a separate control of these dynamics can be made [5-9].

With such an approximation, one neglects the effects of the induced electromotive voltages created by the rotation of the motor and the coupling between the phases of the motor. 
These phenomenas (couplings and induced electromotive voltages) are obvious in the electrical equations :

$$
\begin{aligned}
\frac{\mathrm{d}}{\mathrm{d} t}\left[\begin{array}{c}
i_{\mathrm{d}} \\
i_{\mathrm{q}}
\end{array}\right]=\left[\begin{array}{cc}
-R / L_{\mathrm{d}} & p \Omega L_{\mathrm{q}} / L_{\mathrm{d}} \\
-p \Omega L_{\mathrm{d}} / L_{\mathrm{q}} & -R / L_{\mathrm{q}}
\end{array}\right]\left[\begin{array}{c}
i_{\mathrm{d}} \\
i_{\mathrm{q}}
\end{array}\right]+ \\
+\left[\begin{array}{cc}
1 / L_{\mathrm{d}} & 0 \\
0 & 1 / L_{\mathrm{q}}
\end{array}\right]\left[\begin{array}{c}
v_{\mathrm{d}} \\
v_{\mathrm{q}}-p \Phi_{\mathrm{f}} \Omega
\end{array}\right]=A\left[\begin{array}{c}
i_{\mathrm{d}} \\
i_{\mathrm{q}}
\end{array}\right]+B\left[\begin{array}{c}
v_{\mathrm{d}} \\
v_{\mathrm{q}}-p \Phi_{\mathrm{f}} \Omega
\end{array}\right]
\end{aligned}
$$

where the indexes $\mathrm{d}$ and $\mathrm{q}$ denote the Park components, $v, i$, respectively denote voltages and currents, $\Omega$ is the mechanical speed, $\phi_{\mathrm{f}}$ is the flux created by the inductor, $L_{\mathrm{d}}$ and $L_{\mathrm{q}}$ are the inductances, $R$ the statoric resistance, and $p$ the number of pairs of poles.

We can see two non-linearities : the multiplication with $\Omega$ in the electrical equations, and the $i_{\mathrm{d}} \cdot i_{\mathrm{q}}$ term in the expression of the torque :

$$
C=p\left(L_{\mathrm{d}}-L_{\mathrm{q}}\right) i_{\mathrm{d}} i_{\mathrm{q}}+p \Phi_{\mathrm{f}} i_{\mathrm{q}} .
$$

Presently, we study methods which take into account these non linearities [10-12], based on recent non linear control methods $[13,14]$. The main problem encountered with these methods is that they require a great calculation time for the control. Thus their implementation is impossible with a general use industrial microprocessor (whose rapidity is about $10 \mathrm{MHz}$ ), and so can only be implemented with a fast Digital Signal Processor (D.S.P.). In this paper, we present a method which has been implemented with a broadly diffused microprocessor (Intel 8086).

We shall discuss in this paper the problems arising from the use of a classical torque controller neglecting the effects of the dynamics of $\Omega$ (we shall study the effects of $\frac{\mathrm{d} \Omega}{\mathrm{d} t}$ on a proportional integral controller in the DQ frame). We shall see that $\frac{\mathrm{d} \Omega}{\mathrm{d} t}$ has a great influence on the steady states of such a torque regulation.

Another well known control method is the optimal control $[15,16]$, which minimizes a quadratic criterion in accordance with the linear state equations. This latter method also does not take into account the variations of the mechanical speed, and thus the obtained torqueacceleration characteristic is not satisfying.

Here, in order to inhibe the influence of the motor acceleration on the torque control loop, we develop a method based on linear automatics theory (decoupling by state feedback [15]). Our purpose is to compense the effects of $\Omega$ (and thus the effects of its dynamics $\frac{\mathrm{d} \Omega}{\mathrm{d} t}$ ), and then to impose the closed loop behaviour of the chosen outputs (pole placing).

We shall compare the obtained «total compensation controller » to the PI controller in the D-Q frame.

Then, we shall test the robustness of the total compensation controller against poor knowledge of the speed measurement. As we shall see, the precision of this measurement has a great influence on the behaviour of our system. We shall then present an alternative to this controller which involves integrators and resolves this problem. This last controller has been implemented and gives very promising results.

\section{The proportional-integral torque controller, in the $D-Q$ frame.}

The idea of such a controller is that if $\Omega$ is constant, then a proportional integral regulation on the reconstructed state variables $i_{\mathrm{d}}$ and $i_{\mathrm{q}}$, cancels any static error on these currents. We can see in figure 1 the principle of a regulation in the D-Q frame, and in figure $2 a$ the principle of 


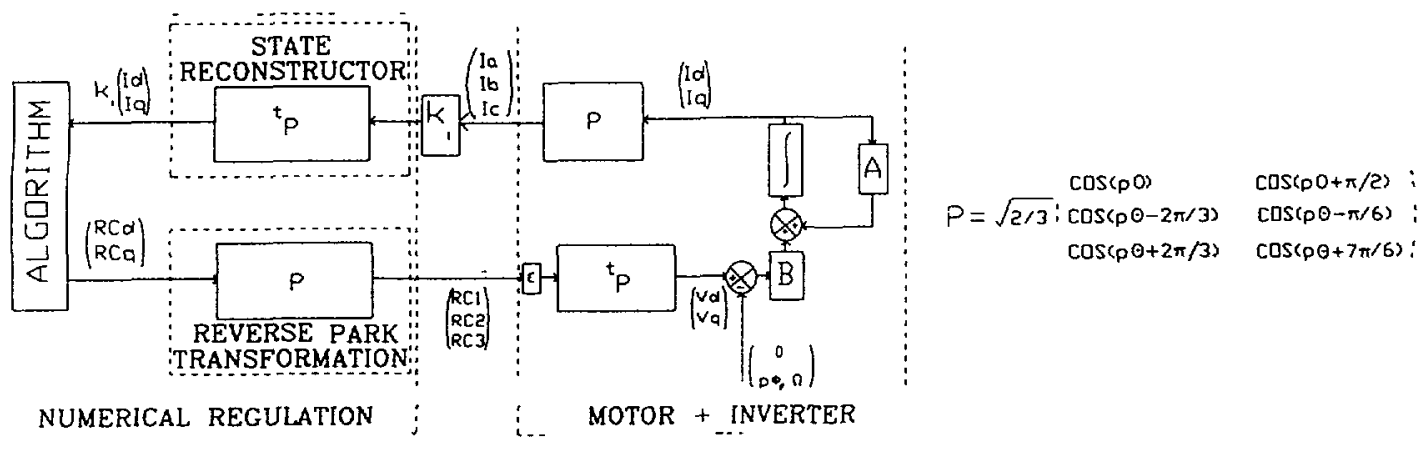

Fig. 1. - Synchronous servomotor. Principle of a D-Q frame control.
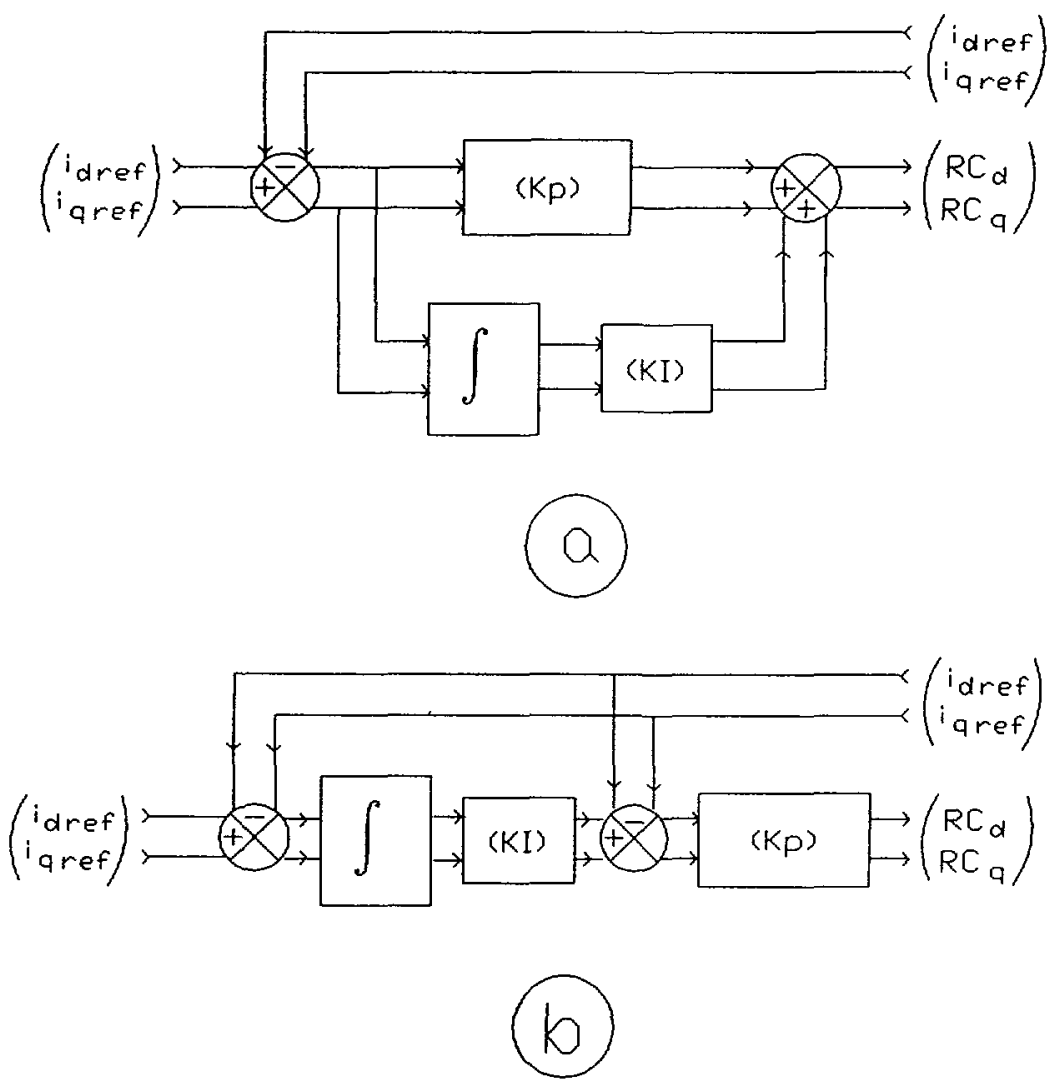

Fig. 2. - a) P.I. controller in the D-Q frame. b) I.P. controller in the D-Q frame.

a proportional integral controller ( $i_{\mathrm{dref}}$ is put to zero and $i_{\mathrm{q} \text { ref }}$ is calculated by the speed controller).

$[R C 11$

$R C 2$ is the PWM imposed by the control algorithm to the inverter, $E$ is the inverter $R C 3$ ]

continuous voltage, and $k_{\mathrm{i}}$ the gain of the current sensor ( $E$ and $k_{1}$ are specified in appendix). 
A state reconstructor is necessary to calculate $i_{d}$ and $i_{q}$ from the three-phase currents. A reverse Park transformation is also needed to obtain the three-phase voltages which must be imposed on the motor through the inverter.

With such a controller, the closed loop state equations become :

$$
\begin{aligned}
& \frac{\mathrm{d} i_{\mathrm{d}}}{\mathrm{d} t}=\frac{-R}{L_{\mathrm{d}}} i_{\mathrm{d}}+\frac{p \Omega L_{\mathrm{q}}}{L_{\mathrm{d}}} i_{\mathrm{q}}+\frac{E k_{\mathrm{i}} K_{\mathrm{p}}\left(i_{\mathrm{d} \text { ref }}-i_{\mathrm{d}}\right)}{L_{\mathrm{d}}}+\frac{E k_{\mathrm{i}} K_{\mathrm{I}} \int\left(i_{\mathrm{d} \text { ref }}-i_{\mathrm{d}}\right) \mathrm{d} t}{L_{\mathrm{d}}} \\
& \frac{\mathrm{d} i_{\mathrm{q}}}{\mathrm{d} t}=\frac{-R}{L_{\mathrm{q}}} i_{\mathrm{q}}-\frac{p \Omega L_{\mathrm{d}}}{L_{\mathrm{q}}} i_{\mathrm{d}}+\frac{E k_{\mathrm{i}} K_{\mathrm{p}}\left(i_{\mathrm{q} \text { ref }}-i_{\mathrm{q}}\right)}{L_{\mathrm{q}}}+\frac{E k_{\mathrm{i}} K_{\mathrm{I}} \int\left(i_{\mathrm{q} \text { ref }}-i_{\mathrm{q}}\right) \mathrm{d} t}{L_{\mathrm{q}}}-\frac{p \Phi_{\mathrm{f}} \Omega}{L_{\mathrm{q}}}
\end{aligned}
$$

and

$\frac{\mathrm{d} i_{\mathrm{d}}^{2}}{\mathrm{~d} t^{2}}=\frac{-R_{\mathrm{s}}}{L_{\mathrm{d}}} \frac{\mathrm{d} i_{\mathrm{d}}}{\mathrm{d} t}+\frac{p \Omega L_{\mathrm{q}}}{L_{\mathrm{d}}} \frac{\mathrm{d} i_{\mathrm{q}}}{\mathrm{d} t}+\frac{p L_{\mathrm{q}} i_{\mathrm{q}}}{L_{\mathrm{d}}} \frac{\mathrm{d} \Omega}{\mathrm{d} t}-\frac{E k_{\mathrm{l}} K_{\mathrm{p}}}{L_{\mathrm{d}}} \frac{\mathrm{d} i_{\mathrm{d}}}{\mathrm{d} t}+\frac{E k_{1} K_{1}\left(i_{\mathrm{d} \text { ref }}-i_{\mathrm{d}}\right)}{L_{\mathrm{d}}}$

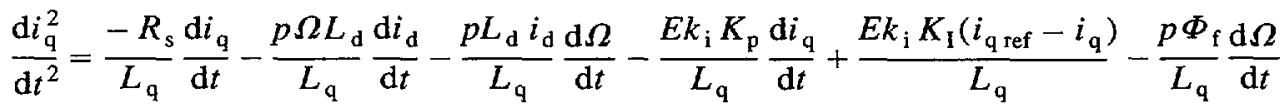

As foreseen, if $\Omega$ is constant, the steady states of such a regulation is :

$$
i_{\mathrm{d}}=i_{\mathrm{d} \text { ref }}, \quad i_{\mathrm{q}}=i_{\mathrm{q} \text { ref }} .
$$

An interesting characteristic of the controller is its behaviour with a constant acceleration (it is practically the case of a motor without any load). With $\gamma=\frac{\mathrm{d} \Omega}{\mathrm{d} t}$, we get :

$$
\begin{aligned}
& i_{d \infty}=i_{\mathrm{d} \text { ref }}\left\{1-\frac{L_{\mathrm{d}} L_{\mathrm{q}} p^{2} \gamma^{2}}{\left(E k_{\mathrm{l}} K_{\mathrm{I}}\right)^{2}} \beta\right\}+\frac{p L_{\mathrm{q}} \gamma}{E k_{\mathrm{i}} K_{\mathrm{I}}} \beta i_{\mathrm{q} \text { ref }}-\frac{L_{\mathrm{q}} \Phi_{\mathrm{f}} p^{2} \gamma^{2}}{\left(E k_{\mathrm{l}} K_{\mathrm{I}}\right)^{2}} \beta \\
& i_{\mathrm{q} \infty}=\beta i_{\mathrm{q} \text { ref }}-\frac{p L_{\mathrm{d}} \gamma}{E k_{\mathrm{i}} K_{\mathrm{I}}} \beta i_{\mathrm{d} \text { ref }}-\frac{p \Phi_{\mathrm{f}} \gamma}{E k_{\mathrm{i}} K_{\mathrm{I}}} \beta
\end{aligned}
$$

with :

$$
\beta=\frac{\left(E k_{\mathrm{i}} K_{\mathrm{I}}\right)^{2}}{\left(E k_{\mathrm{i}} K_{\mathrm{I}}\right)^{2}+p^{2} \gamma^{2} L_{\mathrm{d}} L_{\mathrm{q}}}
$$

We can see in figure 3, the evolution of the steady states of the currents $l_{\mathrm{d} 00}$, $i_{\mathrm{q} \infty}$ and the torque, with a constant acceleration of the motor $\left(K_{\mathrm{p}}=\frac{3.5}{256}, K_{\mathrm{I}}=\frac{660}{256}\right.$, $i_{\mathrm{d} \text { ref }}=0 \mathrm{~A}, i_{\mathrm{q} \text { ref }}=2 \mathrm{~A}$, for accelerations from $0 \mathrm{rd} / \mathrm{s}^{2}$ to the maximum acceptable acceleration, corresponding to the maximum torque specified by the constructor (for the unloaded motor)). The characteristics of the motor are given in the appendix. The method which permits to determine gains $K_{\mathrm{p}}$ and $K_{\mathrm{I}}$ is detailled in [17].

Figure 4 is an experimental implementation of this controller, where we measured $\Omega$ and the state reconstruction $i_{\mathrm{q}}$, on a torque step experiment (step on $i_{\mathrm{q} \text { ref }}$ from 6.25 A to $12.5 \mathrm{~A}$ ). The static error on $i_{\mathrm{q}}$ is obvious when the motor acceleration is noticeable.

To solve such a problem, a first solution consists in compensating the effects of the mechanical speed on the torque regulation, obtaining then the «total compensation controller ». 


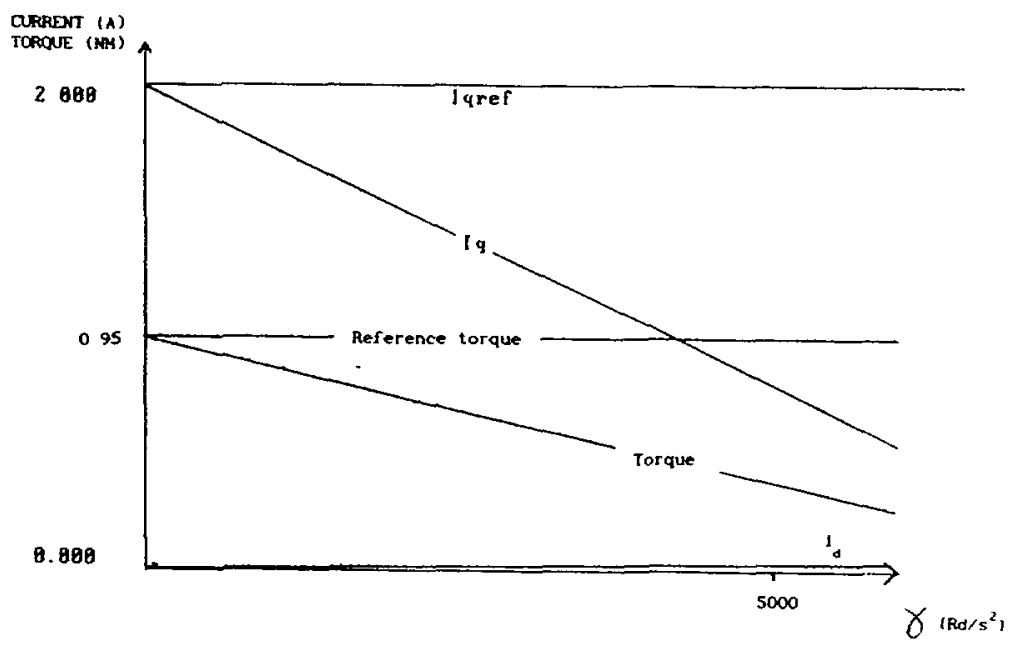

Fig. 3. - P.I. controller in D-Q frame. Influence of $\gamma$. Characteristics $i_{\mathrm{d}}(\gamma), i_{\mathrm{q}}(\gamma)$ and torque $(\gamma)$.

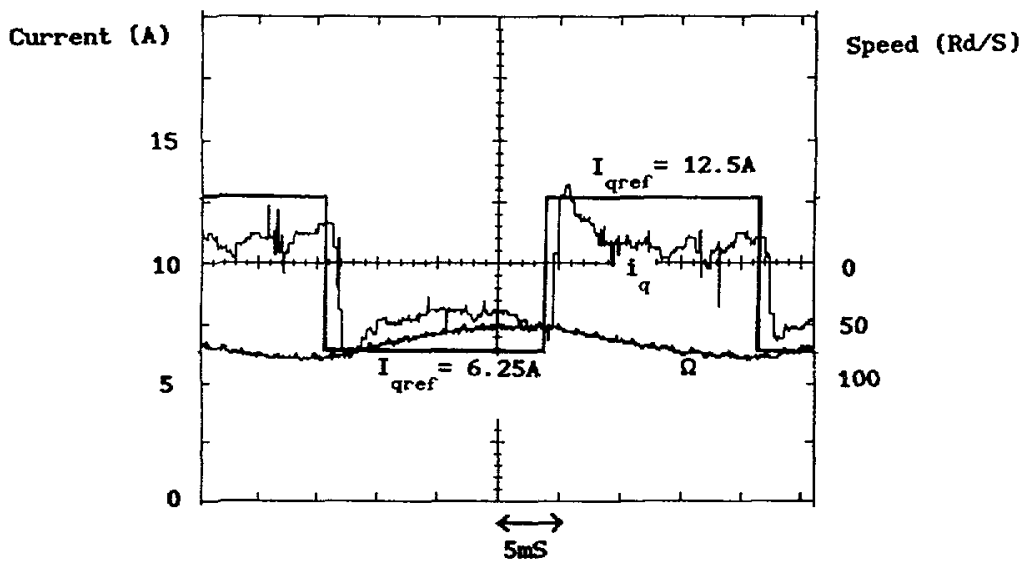

Fig. 4. - P.I. controller in D-Q frame. Influence of $\gamma$. Step experiment on $i_{\mathrm{q}}$. Implementation.

NOTE ABOUT THE I.P. CONTROLLER. - Integral-Proportional controller (I.P. controller, also called P.I. without zero), which structure is recalled on figure $2 b$, is often used instead of P.I. controllers $[7,8]$. Indeed, this structure permits to cancell the influence of the zero during the transients of a step experiment on the torque.

The torque-acceleration characteristic of this controller is given by formulas (6) and (7), on which the term $\left(K_{\mathrm{I}}\right)$ must be replaced by $\left(K_{\mathrm{p}} K_{\mathrm{I}}\right)$. The same problem of an important static error due to the motor acceleration is noticed.

\section{The total compensation controller.}

We shall present in this paragraph the method which permits us to obtain a torque controller which compensates the effects of the dynamics of $\Omega$. We shall then test the robustness of this controller. 
Such a controller allows us to use a successive loops structure, the behaviour of the torque and of the speed being decoupled.

3.1 PRINCIPLE OF THE METHOD. - The aim of the method is to impose the static behaviour $i_{\mathrm{d}}=i_{\mathrm{dref}}$ and $i_{q}=i_{q \text { ref }}$, with a dynamics for the error described by the equations :

$$
\begin{aligned}
& \frac{\mathrm{d} e_{\mathrm{d}}}{\mathrm{d} t}=-K_{1} e_{\mathrm{d}} \text { with } e_{\mathrm{d}}=i_{\mathrm{d} \text { ref }}-i_{\mathrm{d}} \\
& \frac{\mathrm{d} e_{\mathrm{q}}}{\mathrm{d} t}=-K_{2} e_{\mathrm{q}} \text { with } e_{\mathrm{q}}=i_{\mathrm{q} \text { ref }}-i_{\mathrm{q}} .
\end{aligned}
$$

The observation of the state equation (1), makes obvious the fact that the only way to obtain the behaviour (8) is to impose the control :

$$
\left[\begin{array}{c}
v_{\mathrm{d}} \\
v_{\mathrm{q}}-p \Phi_{\mathrm{f}} \Omega
\end{array}\right]=B^{-1}\left[-A\left[\begin{array}{c}
i_{\mathrm{d}} \\
i_{\mathrm{q}}
\end{array}\right]+\left[\begin{array}{c}
K_{\mathrm{t}}\left(i_{\mathrm{dref}}-i_{\mathrm{d}}\right) \\
K_{2}\left(i_{\mathrm{q} \text { ref }}-i_{\mathrm{q}}\right)
\end{array}\right]\right] .
$$

We must observe that this control can be applied because the decoupling matrix $B$ is always non-singular.

It is now very easy to place the poles of the system, by adjusting the coefficients $K_{1}$ and $K_{2}$. We impose, with such a method the following convergence:

$$
\begin{aligned}
& \stackrel{t \rightarrow \infty}{e_{\mathrm{d}} \rightarrow 0} \Rightarrow \stackrel{t \rightarrow \infty}{i_{\mathrm{d}} \rightarrow I_{\mathrm{d} \mathrm{ref}}} \\
& e_{\mathrm{q}} \rightarrow \stackrel{+\infty}{\rightarrow} 0 \Rightarrow i_{\mathrm{q}} \rightarrow I_{\mathrm{q} \text { ref }} .
\end{aligned}
$$

From the equation (9), we get the control law for $V_{\mathrm{d}}$ and $V_{\mathrm{q}}$.

$$
\begin{aligned}
& V_{\mathrm{d}}=R i_{\mathrm{d}}-p L_{\mathrm{q}} \Omega i_{\mathrm{q}}-K_{\mathrm{l}} L_{\mathrm{d}} i_{\mathrm{d}} \\
& V_{\mathrm{q}}=R i_{\mathrm{q}}+p L_{\mathrm{d}} \Omega i_{\mathrm{d}}+K_{2} L_{\mathrm{q}}\left(I_{\mathrm{q} \text { ref }}-i_{\mathrm{q}}\right)+p \Phi_{\mathrm{f}} \Omega .
\end{aligned}
$$

This controller is a judicious alternative to the classical proportional integral controller in the D-Q frame :

- in the usual proportional integral controller, the induced electromotive voltages, and the coupling between the axis $d$ and $q$ are compensated by the integrators;

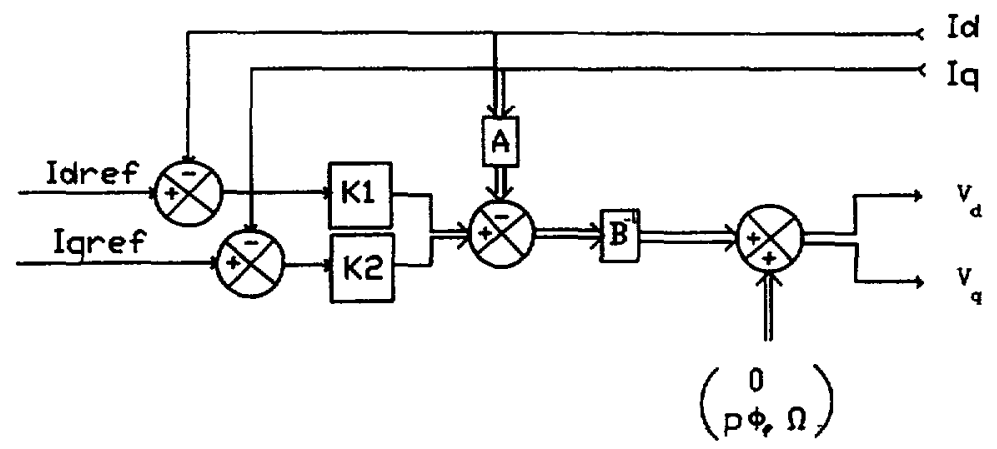

Fig. 5. - Total compensation controller. 
- the total compensation controller, instead of using integrators, compensates directly these perturbations linked to $\Omega$, these one being computed in real time. Thus this compensation can manage high dynamics on $\Omega$ (the closed loop system being described by the equation (8) does not depend on $\Omega$ ). The behaviour obtained for the closed loop system is the behaviour of a first order system, and the steady states for $i_{\mathrm{d}}$ and $i_{\mathrm{q}}$ will be respectively $i_{\mathrm{d} \text { ref }}$ and $i_{\mathrm{q} \text { ref }}$ for any speed and any acceleration.

We can see in figure 5 the scheme of this total compensation controller.

3.2 RESUlTs. - For the implementation of this controller, we used a direct digital control strategy. We mean by this that each variable which intervenes in the controller algorithm, is measured and immediately converted by an analog to digital converter linked to a microprocessor board. The microprocessor provides successively :

- the Park components $i_{\mathrm{d}}$ and $i_{\mathrm{q}}$ of the three-phase currents of the motor;

- the result of the control algorithm (i.e. the necessary voltages $V_{\mathrm{d}}$ and $V_{\mathrm{q}}$ );

- the reference three-phase voltages computed from $V_{d}$ and $V_{\mathrm{q}}$ by the reverse Park transformation [8].

We present in figure 6 a simulation of a step experiment on the motor, $I_{\mathrm{q} \text { ref }}$ changing from $0 \mathrm{~A}$ to $10 \mathrm{~A}$, while $I_{\mathrm{d} \text { ref }}$ stays at $0 \mathrm{~A}$. The simulation has been done with the values of the motor parameters given in appendix, and with $K_{1}$ and $K_{2}$ equal to 800 . The $5 \%$ response time of the current $i_{\mathrm{q}}$ is very rapid (about $2.5 \mathrm{~ms}$ ). In this simulation, we take into account the presence of a zero-order-holder and a time delay of a sampling period (due to the calculation time), that we cannot avoid in the implementation.

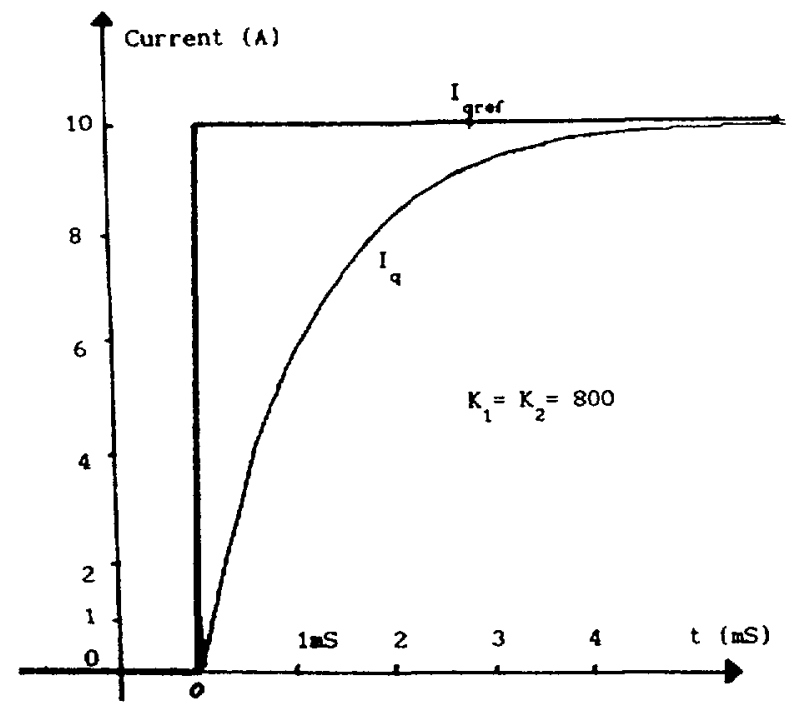

Fig. 6. - Total compensation controller. Simulation of a step experiment on $i_{\mathrm{q}}$.

\subsection{ROBUSTNESS OF THE CONTROLLER.}

3.3.1 Robustness of the controller with respect to inacurracy of parameters and measurements.

- The compensation terms in equation (11) have a limited accuracy. Indeed the machine parameters are imprecisely known, and may vary. Let $L_{\mathrm{dc}}, L_{\mathrm{qc}}, R_{\mathrm{c}}, \Phi_{\mathrm{fc}}$ be respectively the values used in the control algorithm for $L_{\mathrm{d}}, L_{\mathrm{q}}, R, \Phi_{\mathrm{f}}$. 
Furthermore the currents, speed and position measurement are noised. Let $i_{\mathrm{dm}}$, $i_{\mathrm{qm}}, \Omega_{\mathrm{m}}$ be respectively the measurement of $i_{\mathrm{d}}, i_{\mathrm{q}}, \Omega$.

By applying the control law (11) to the state equation (1), we obtain the closed loop behaviour :

$$
\begin{aligned}
\frac{\mathrm{d} i_{\mathrm{d}}}{\mathrm{d} t}= & K_{1} \frac{L_{\mathrm{dc}}}{L_{\mathrm{d}}}\left(I_{\mathrm{d} \text { ref }}-i_{\mathrm{dm}}\right)+\frac{R_{\mathrm{c}} i_{\mathrm{dm}}-R i_{\mathrm{d}}}{L_{\mathrm{d}}}+p \frac{L_{\mathrm{q}} \Omega i_{\mathrm{q}}-L_{\mathrm{qc}} \Omega_{\mathrm{m}} i_{\mathrm{qm}}}{L_{\mathrm{d}}} \\
\frac{\mathrm{d} i_{\mathrm{q}}}{\mathrm{d} t}= & K_{2} \frac{L_{\mathrm{qc}}}{L_{\mathrm{q}}}\left(I_{\mathrm{q} \text { ref }}-i_{\mathrm{qm}}\right)+\frac{R_{\mathrm{c}} i_{\mathrm{qm}}-R i_{\mathrm{q}}}{L_{\mathrm{q}}}+p \frac{L_{\mathrm{dc}} \Omega_{\mathrm{m}} i_{\mathrm{dm}}-L_{\mathrm{d}} \Omega i_{\mathrm{d}}}{L_{\mathrm{q}}} \\
& -p\left[\frac{\Phi_{\mathrm{f}} \Omega}{L_{\mathrm{q}}}-\frac{\Phi_{\mathrm{fc}} \Omega_{\mathrm{m}}}{L_{\mathrm{qc}}}\right] .
\end{aligned}
$$

With the gains $K_{1}$ and $K_{2}$ proposed in the previous paragraph, with the parameters values given in appendix, for $10 \%$ error on parameters and measurements, we have :

$$
\begin{aligned}
& \frac{R_{\mathrm{c}}}{L_{\mathrm{d}}}, \frac{R}{L_{\mathrm{d}}}, \frac{p L_{\mathrm{q}} \Omega}{L_{\mathrm{d}}}, \frac{p L_{\mathrm{qc}} \Omega_{\mathrm{m}}}{L_{\mathrm{d}}} \text { negligible beside } K_{1} \frac{L_{\mathrm{dc}}}{L_{\mathrm{d}}} \\
& \frac{R_{\mathrm{c}}}{L_{\mathrm{q}}}, \frac{R}{L_{\mathrm{q}}}, \frac{p L_{\mathrm{d}} \Omega}{L_{\mathrm{q}}}, \frac{p L_{\mathrm{dc}} \Omega_{\mathrm{m}}}{L_{\mathrm{q}}} \quad \text { negligible beside } K_{2} \frac{L_{\mathrm{qc}}}{L_{\mathrm{q}}}
\end{aligned}
$$

We get then :

$$
\begin{aligned}
\frac{\mathrm{d} i_{\mathrm{d}}}{\mathrm{d} t} & =K_{1} \frac{L_{\mathrm{dc}}}{L_{\mathrm{d}}}\left(I_{\mathrm{d} \mathrm{ref}}-i_{\mathrm{dm}}\right) \\
\frac{\mathrm{d} i_{\mathrm{q}}}{\mathrm{d} t} & \simeq K_{2} \frac{L_{\mathrm{qc}}}{L_{\mathrm{q}}}\left(I_{\mathrm{q} \mathrm{ref}}-i_{\mathrm{qm}}\right)-p\left[\frac{\Phi_{\mathrm{f}} \Omega}{L_{\mathrm{q}}}-\frac{\Phi_{\mathrm{fc}} \Omega_{\mathrm{m}}}{L_{\mathrm{qc}}}\right] .
\end{aligned}
$$

We realize here that the closed loop behaviour is highly perturbed by the term :

$$
\xi=\left[\frac{\Phi_{\mathrm{f}} \Omega}{L_{\mathrm{q}}}-\frac{\Phi_{\mathrm{fc}} \Omega_{\mathrm{m}}}{L_{\mathrm{qc}}}\right] .
$$

To cancell this term, one needs a perfect knowing of $\Phi_{\mathrm{f}}$ and $L_{\mathrm{q}}$, and a perfect measurement of $\Omega$. If it is not the case, the influence of $\xi$ can be pointed out by means of a variation of $\left(\Omega_{\mathrm{m}}-\Omega\right.$ ) (the two others terms $\Phi_{\mathrm{fc}}$ and $L_{\mathrm{qc}}$ being put to $\Phi_{\mathrm{f}}$ and $L_{\mathrm{q}}$ ). Thus, we will examine in the next paragraph, the robustness of the «total compensation controller " with respect to an inaccurate speed measurement.

3.3.2 Robustness of the controller with respect to a poor knowledge of the speed of the motor.

3.3.2.1 Calculation of the static error. - In order to compensate the perturbations linked to $\Omega$, the total compensation controller requires a precise measurement of the mechanical speed $\Omega_{\mathrm{m}}$. We suppose in this paragraph that this speed measurement $\left(\Omega_{\mathrm{m}}\right)$ is not perfect $\left(\Omega_{\mathrm{m}} \neq \equiv\right)$, and we shall analyse the consequences of this inaccuracy on our regulation.

The model of the closed loop taking into account the difference between $\Omega$ and $\Omega_{\mathrm{m}}$, can be deduced from the state equation (1) and the equation of the control (11). We get :

$$
\begin{array}{r}
\frac{\mathrm{d}}{\mathrm{d} t}\left[\begin{array}{l}
i_{\mathrm{d}} \\
i_{\mathrm{q}}
\end{array}\right]=A\left[\begin{array}{l}
i_{\mathrm{d}} \\
i_{\mathrm{q}}
\end{array}\right]+B\left\{\left[\begin{array}{c}
R i_{\mathrm{d}}-p L_{\mathrm{q}} \Omega_{\mathrm{m}} i_{\mathrm{q}}-K_{1} L_{\mathrm{d}} i_{\mathrm{d}} \\
R i_{\mathrm{q}}+p L_{\mathrm{d}} \Omega_{\mathrm{m}} i_{\mathrm{d}}+K_{2} L_{\mathrm{q}}\left(i_{\mathrm{q} \text { ref }}-i_{\mathrm{q}}\right)+p \Phi_{\mathrm{f}} \Omega_{\mathrm{m}}
\end{array}\right]+\right. \\
\left.+\left[\begin{array}{c}
0 \\
-p \Phi_{\mathrm{f}} \Omega
\end{array}\right]\right\}=A_{\mathrm{bf}}\left[\begin{array}{c}
i_{\mathrm{d}} \\
i_{\mathrm{q}}
\end{array}\right]+B_{\mathrm{bf}}
\end{array}
$$


where :

$$
A_{\mathrm{bf}}=\left[\begin{array}{cc}
-K_{1} & -\frac{p L_{\mathrm{q}}}{L_{\mathrm{d}}}\left(\Omega_{\mathrm{m}}-\Omega\right) \\
\frac{p L_{\mathrm{d}}}{L_{\mathrm{q}}}\left(\Omega_{\mathrm{m}}-\Omega\right) & -K_{2}
\end{array}\right] \text { and } B_{\mathrm{bf}}=\left[\begin{array}{c}
0 \\
p \Phi_{\mathrm{f}}\left(\Omega_{\mathrm{m}}-\Omega\right)
\end{array}\right]
$$

We can see that if we do not neglect the fact that the speed cannot be perfectly measured, the decoupling between the axis $d$ and $q$, and the compensation of the induced electromotive voltages are not total. We can get the static error of our regulation if we calculate the steady states for $i_{\mathrm{d}}$ and $i_{\mathrm{q}}$. We can write, from the equation (14):

$$
\left[\begin{array}{l}
i_{\mathrm{d} \infty} \\
i_{\mathrm{q} \infty}
\end{array}\right]=-A_{\mathrm{bf}}^{-1} B_{\mathrm{bf}} .
$$

We remark here that $A_{\mathrm{bf}}$ is always non-singular because its determinant, whose value is $K_{1} K_{2}+p^{2}\left(\Omega_{\mathrm{m}}-\Omega\right)^{2}$, never reaches 0 .

So, we have :

$$
\begin{aligned}
i_{\mathrm{d} \infty}= & \frac{-p L_{\mathrm{q}}}{K_{1} L_{\mathrm{d}}}\left(\Omega_{\mathrm{m}}-\Omega\right) \\
1+\frac{p^{2}\left(\Omega_{\mathrm{m}}-\Omega\right)^{2}}{K_{1} K_{2}} & \left.i_{\mathrm{q} \text { ref }}+\frac{p \Phi_{\mathrm{f}}}{L_{\mathrm{q}} K_{2}}\left(\Omega_{\mathrm{m}}-\Omega\right)\right\} \\
i_{\mathrm{q} \infty}= & \frac{1}{1+\frac{p^{2}\left(\Omega_{\mathrm{m}}-\Omega\right)^{2}}{K_{1} K_{2}}}\left\{i_{\mathrm{q} \mathrm{ref}}+\frac{p \Phi_{\mathrm{f}}}{L_{\mathrm{q}} K_{2}}\left(\Omega_{\mathrm{m}}-\Omega\right)\right\} .
\end{aligned}
$$

3.3.2.2 Simulation results concerning the robustness with respect to $\Omega$. - In order to test the robustness of the total compensation controller, we made a simulation where we add to the measurement of the analog to digital converter providing $\Omega_{\mathrm{m}}$, a constant noise of $10 \%$ of the maximum measurable mechanical speed $\left(\Omega_{\max }=230 \mathrm{rd} / \mathrm{s}\right)$.

With the values of the motor parameters given in appendix, with tracking references $I_{\mathrm{d} \text { ref }}=0$ and $I_{\mathrm{q} \text { ref }}=10 \mathrm{~A}$, with $K_{1}$ and $K_{2}$ equal to 800 , and for a speed of the motor of $200 \mathrm{rd} / \mathrm{s}$, we obtain :

$$
\begin{aligned}
i_{\mathrm{d} \infty}= & +1 \mathrm{~A} \text { in the case of } \mathrm{a}-10 \% \text { error } \\
& -3 \mathrm{~A} \text { in the case of } \mathrm{a}+10 \% \text { error } \\
i_{\mathrm{q} \infty}= & 4.98 \mathrm{~A} \text { in the case of } \mathrm{a}-10 \% \text { error } \\
& 14.83 \mathrm{~A} \text { in the case of } \mathrm{a}+10 \% \text { error } .
\end{aligned}
$$

We can see in figure 7 this test of robustness. In the same figure, we show the influence of a random disturbance noise on the speed measurement (maximum amplitude of the noise : $0.1 \Omega_{\max }$ ). The time constant of the torque closed loop permits to filter this H.F. noise : curve $i_{\mathrm{q}}(3)$ evoluates between curves $i_{\mathrm{q}}(1)$ and $i_{\mathrm{q}}(2)$ but does not reach them.

So, we realize here that this controller is very sensitive to a constant error on the speed measurement. We cannot accept such a static error on $i_{\mathrm{q}}$, hindering us in controlling the torque of the machine. Let us observe that this static error comes mainly from the induced electromotive voltage $p \Phi_{\mathrm{f}} \Omega / L_{\mathrm{q}}$ that we cannot perfectly compensate and which can reach 


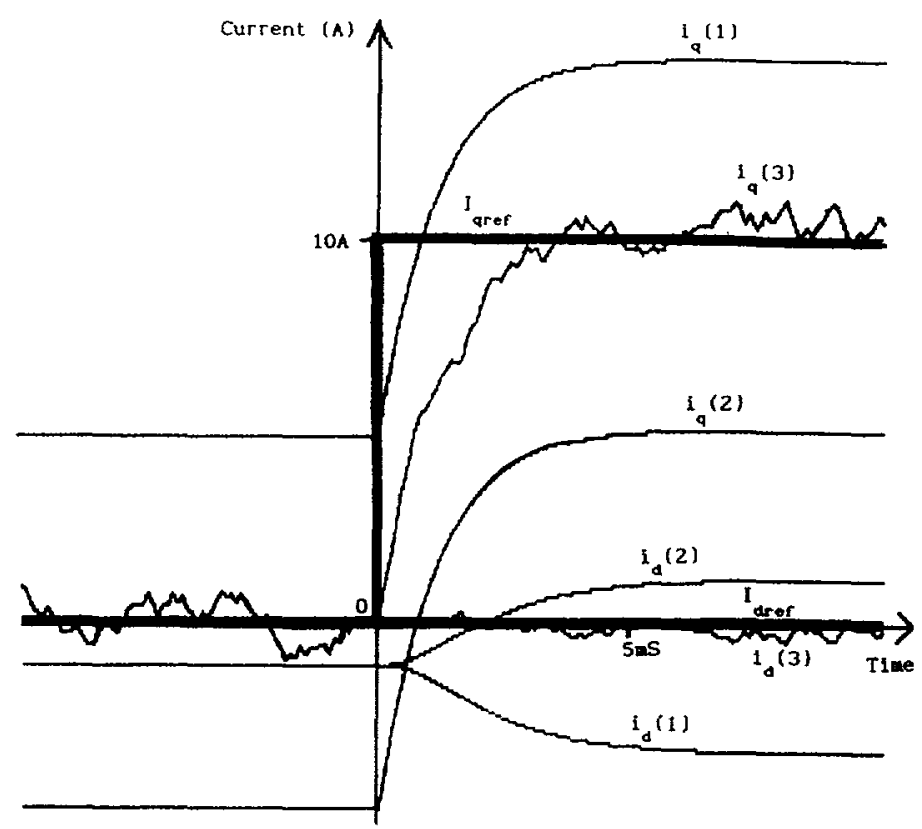

Fig. 7. - Total compensation controller. Simulation test of the robustness, case (1): $\Omega_{\mathrm{m}}=\Omega+0.1 \Omega_{\max }$, case (2): $\Omega_{\mathrm{m}}=\Omega-0.1 \Omega_{\max }$, case (3) : $\Omega_{\mathrm{m}}=\Omega+$ random noise.

quite high values. Facing this problem, we had to find an alternative to this controller. A solution is the total compensation controller with integrators.

\section{The total compensation controller with integrators.}

The idea is to use the total compensation controller, but to remove the static error coming from an inaccurate knowledge of the motor speed, by using integrators, in order to improve the robustness.

The main difference between this new strategy and the classical proportional integral controller usually met in industrial applications (see paragraph 2 , and [1]), is that here, one only integrates a residue coming from the fact that the speed cannot be perfectly known for the decoupling and the compensation of the induced electromotive voltages. Only integrating this residue permits us to reduce considerably the static error created by the dynamics of the mechanical speed, on the steady states of $i_{d}$ and $i_{q}$.

4.1 PRINCIPLE OF THE METHOD. - According to the previous considerations, the aim of the method presented here is to impose the steady state $i_{\mathrm{d} \infty}=i_{\mathrm{d} \text { ref }}$ and $i_{\mathrm{q} \infty}=i_{\mathrm{q} \text { ref }}$, with integrators in the differential equations describing the evolution of the error:

$$
\begin{aligned}
& \frac{\mathrm{d} e_{\mathrm{d}}}{\mathrm{d} t}=K_{11} e_{\mathrm{d}}+K_{12} \int_{0}^{t} e_{\mathrm{d}} \mathrm{d} t \text { with } e_{\mathrm{d}}=i_{\mathrm{d} \text { ref }}-i_{\mathrm{d}} \\
& \frac{\mathrm{d} e_{\mathrm{q}}}{\mathrm{d} t}=K_{21} e_{\mathrm{q}}+K_{22} \int_{0}^{t} e_{\mathrm{q}} \mathrm{d} t \text { with } e_{\mathrm{q}}=i_{\mathrm{q} \text { ref }}-i_{\mathrm{q}} .
\end{aligned}
$$

The integrators will permit us to cancell any static error coming from an inaccurate 
compensation of the effects of $\Omega$ (problems of robustness with respect to an imprecise speed measurement).

Thus, as explained in the paragraph 3.1 , we easily determine the only control permitting us to obtain such a behaviour :

$$
\left[\begin{array}{l}
v_{\mathrm{d}} \\
v_{\mathrm{q}}-p \Phi_{\mathrm{f}} \Omega
\end{array}\right]=B^{-1}\left[-A\left[\begin{array}{l}
i_{\mathrm{d}} \\
i_{\mathrm{q}}
\end{array}\right]+\left[\begin{array}{l}
K_{11} e_{\mathrm{d}}+K_{12} \int_{0}^{t} e_{\mathrm{d}} \mathrm{d} t \\
K_{21} e_{\mathrm{q}}+K_{22} \int_{0}^{t} e_{\mathrm{q}} \mathrm{d} t
\end{array}\right]\right] .
$$

Thus, the necessary control voltages are :

$$
\begin{aligned}
& V_{\mathrm{d}}=R i_{\mathrm{d}}-p L_{\mathrm{q}} \Omega i_{\mathrm{q}}-K_{11} L_{\mathrm{d}} i_{\mathrm{d}}-K_{12} L_{\mathrm{d}} \int_{0}^{t} i_{\mathrm{d}} \mathrm{d} t \\
& V_{\mathrm{q}}=R i_{\mathrm{q}}+p L_{\mathrm{d}} \Omega i_{\mathrm{d}}+K_{21} L_{\mathrm{q}}\left(i_{\mathrm{q} \text { ref }}-i_{\mathrm{q}}\right)+K_{22} L_{\mathrm{q}} \int_{0}^{t}\left(i_{\mathrm{q} \text { ref }}-i_{\mathrm{q}}\right) \mathrm{d} t+p \Phi_{\mathrm{f}} \Omega .
\end{aligned}
$$

The behaviour of the system is then linear, and the coefficients $K_{11}, K_{12}, K_{21}$ and $K_{22}$ are chosen to obtain the desired transients. We obtain two independent second order differential equations describing the behaviour of our two state variables $i_{\mathrm{d}}$ and $i_{\mathrm{q}}$.

$$
\begin{aligned}
& \frac{\mathrm{d} e_{\mathrm{d}}^{2}}{\mathrm{~d} t^{2}}=K_{11} \frac{\mathrm{d} e_{\mathrm{d}}}{\mathrm{d} t}+K_{12} e_{\mathrm{d}} \text { with } e_{\mathrm{d}}=i_{\mathrm{d} \text { ref }}-i_{\mathrm{d}} \\
& \frac{\mathrm{d} e_{\mathrm{q}}^{2}}{\mathrm{~d} t^{2}}=K_{21} \frac{\mathrm{d} e_{\mathrm{q}}}{\mathrm{d} t}+K_{22} e_{\mathrm{q}} \text { with } e_{\mathrm{q}}=i_{\mathrm{q} \text { ref }}-i_{\mathrm{q}} .
\end{aligned}
$$

We can obtain the desired poles of our system from these two equations. We can see in figure 8 the structure of this controller.

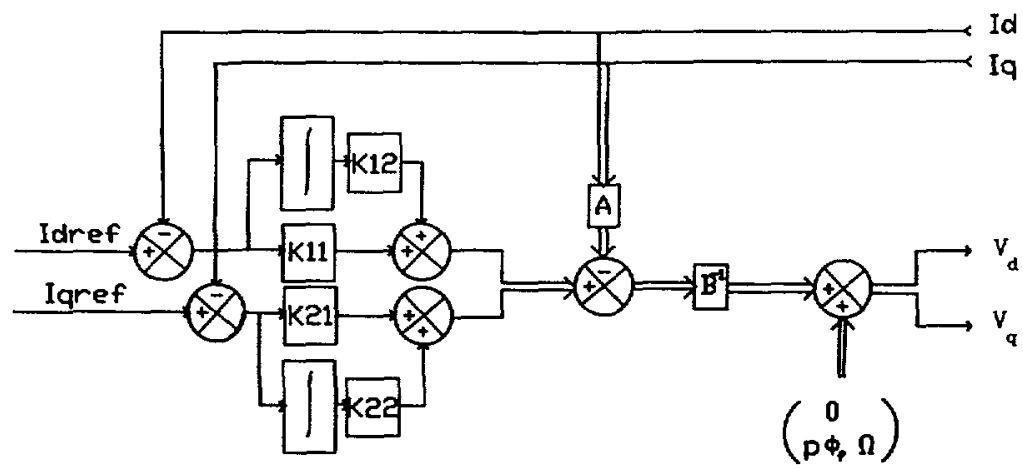

Fig. 8. - Total compensation controller with integrators.

4.2 Simulation TEST OF THE ROBUSTNESS. - We tested the robustness of the total compensation controller with integrators, to the imprecise measurement of the speed $\Omega$. We want to proove that the controller is robust, so we try it in hard conditions : as in paragraph 3.3.2.2, we add to the measurement $\Omega_{\mathrm{m}}$ of the analog to digital converter, a constant noise of $10 \%$ of its maximum convertion. 
Determination of the torque loop gains. - For a fair comparison between the PI torque controller in the $\mathrm{D}-\mathrm{Q}$ frame and the total compensation controller with integrators, we shall impose same proportional and integral action for the closed loop on the axis $Q$. Through an examination of (3) for the PI torque controller, and (20) associated to (1) for the total compensation controller with integrators, one realizes that we need :

$$
\begin{aligned}
& K_{21}\left(i_{\mathrm{q} \text { ref }}-i_{\mathrm{q}}\right)=\frac{E k_{\mathrm{i}} K_{\mathrm{p}}}{L_{\mathrm{q}}}\left(i_{\mathrm{q} \text { ref }}-i_{\mathrm{q}}\right) \\
& K_{22} \int\left(i_{\mathrm{q} \text { ref }}-i_{\mathrm{q}}\right) \mathrm{d} t=\frac{E k_{\mathrm{1}} K_{\mathrm{I}}}{L_{\mathrm{q}}} \int\left(i_{\mathrm{q} \text { ref }}-i_{\mathrm{q}}\right) \mathrm{d} t
\end{aligned}
$$

We get :

$$
\begin{aligned}
& K_{21}=E k_{\mathrm{i}} K_{\mathrm{p}} / L_{\mathrm{q}} \simeq 3750 \\
& K_{22}=E k_{\mathrm{i}} K_{\mathrm{I}} / L_{\mathrm{q}} \simeq 707100 .
\end{aligned}
$$

In order to obtain the same dynamics in the axis $d$ and $q$, we put :

$$
\begin{aligned}
& K_{11}=K_{21}=3750, \\
& K_{12}=K_{22}=707100 .
\end{aligned}
$$

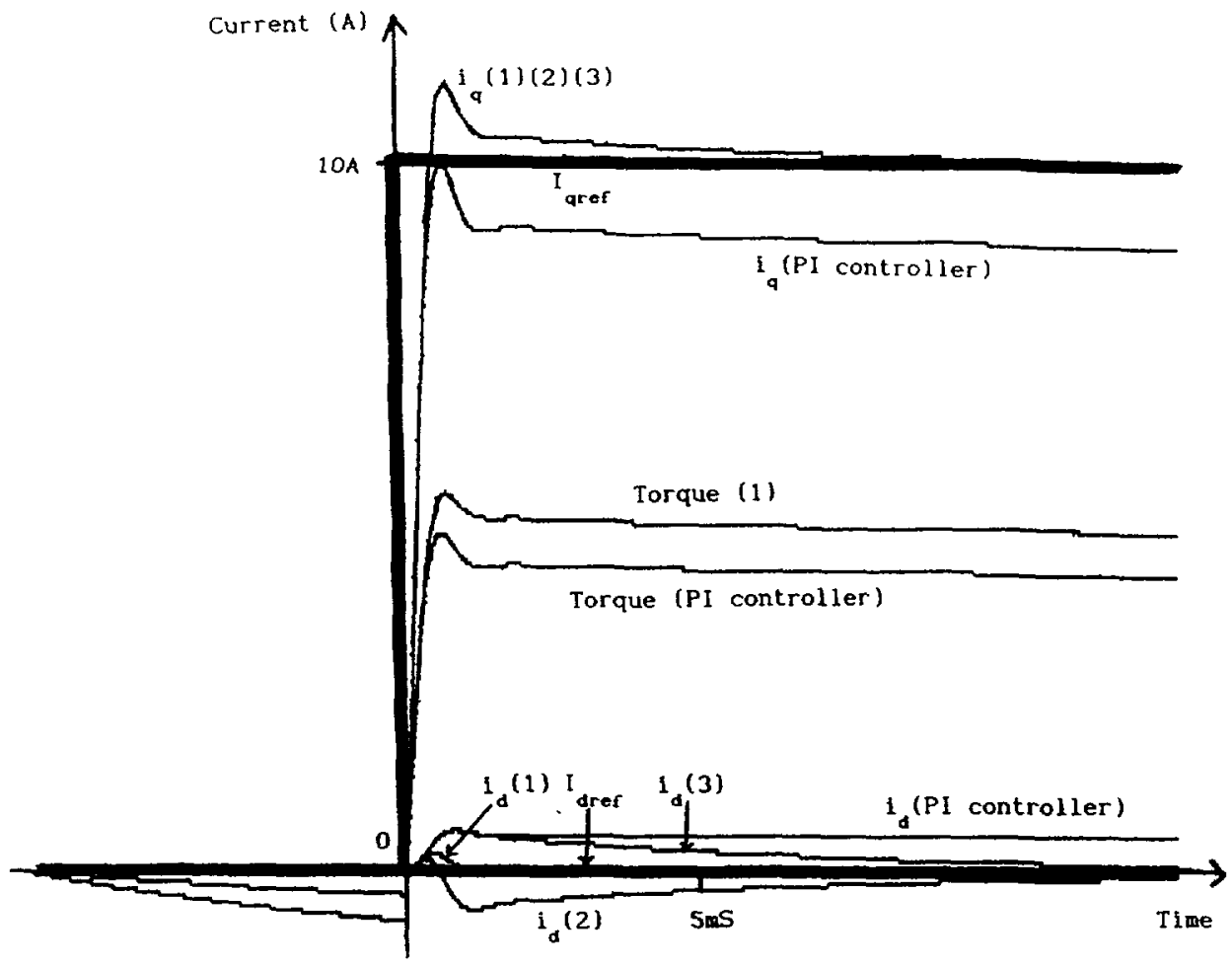

Fig. 9. - Total compensation controller with integrators. Simulation test of the robustness. Constant acceleration $\gamma=5000 \mathrm{rd} / \mathrm{s}^{2}$. Case (1): $\Omega_{\mathrm{m}}=\Omega$. Case (2): $\Omega_{\mathrm{m}}=\Omega+0.1 \Omega_{\max }$. Case (3): $\Omega_{\mathrm{m}}=\Omega-0.1 \Omega_{\max }$ 
Simulation. - With the parameters values of the motor that we use, with tracking references $I_{\mathrm{d} \text { ref }}=0$ and $I_{\mathrm{q} \text { ref }}=10 \mathrm{~A}$, with $K_{11}, K_{21}$ equal to 3750 and $K_{12}, K_{22}$ equal to $707 \times 10^{3}$, and for a constant acceleration $\frac{\mathrm{d} \Omega}{\mathrm{d} t}=5000 \mathrm{rd} / \mathrm{s}^{2}$, we obtain (see Fig. 9) :

- a static error equal to 0 for $i_{\mathrm{d}}$ and $i_{\mathrm{q}}$,

- a response for the step experiment which reaches the steady state in $5.9 \mathrm{~ms}$ (5\% response time).

We must insist on the fact that this simulation takes into account the sampling, the zero order holder and the calculation time necessary for the control algorithm (one sampling period late for the control).

We can see on the same figure the response of the P.I. controller, and notice the $1.5 \mathrm{~A}$ static error for $i_{\mathrm{q}}$, due to the motor acceleration. This static error corresponds to the analytical result ((6) associated to (7)).

We conclude that the total compensation controller with integrators reacts as previously. It is very robust.

4.3 INFLUENCE OF A CONSTANT ACCELERATION. - It is easy to extend the results of paragraph 2 to the total compensation controller with integrators, obtaining the following expressions of the steady states of $i_{\mathrm{d}}$ and $i_{\mathrm{q}}$, for a constant acceleration :

$$
\begin{aligned}
& i_{\mathrm{d} \infty}=i_{\mathrm{d} \text { ref }}\left\{1-\frac{L_{\mathrm{d}} L_{\mathrm{q}} p^{2} \sigma^{2}}{\left(E k_{\mathrm{i}} K_{\mathrm{I}}\right)^{2}} \psi\right\}+\frac{p L_{\mathrm{q}} \sigma}{E k_{1} K_{\mathrm{I}}} \psi i_{\mathrm{q} \text { ref }}-\frac{L_{\mathrm{q}} \Phi_{\mathrm{f}} p^{2} \sigma^{2}}{\left(E k_{\mathrm{i}} K_{\mathrm{I}}\right)^{2}} \psi \\
& i_{\mathrm{q} \infty}=\psi i_{\mathrm{q} \text { ref }}-\frac{p L_{\mathrm{d}} \sigma}{E k_{\mathrm{i}} K_{\mathrm{I}}} \psi i_{\mathrm{d} \text { ref }}-\frac{p \Phi_{\mathrm{f}} \sigma}{E k_{\mathrm{l}} K_{\mathrm{I}}} \psi
\end{aligned}
$$

with :

$$
\begin{aligned}
& \sigma=\frac{\mathrm{d}}{\mathrm{d} t}\left(\Omega-\Omega_{\mathrm{m}}\right) \\
& \psi=\frac{\left(E k_{\mathrm{i}} K_{\mathrm{I}}\right)^{2}}{\left(E k_{\mathrm{i}} K_{\mathrm{I}}\right)^{2}+p^{2} \sigma^{2} L_{\mathrm{d}} L_{\mathrm{q}}}
\end{aligned}
$$

We observe that if the measurement of $\Omega$ is perfect, we get :

$$
\sigma=0 \text {. }
$$

Thus :

$$
\psi=1
$$

and so :

$$
i_{\mathrm{d} \infty}=i_{\mathrm{d} \text { ref }}, \quad i_{\mathrm{q} \infty}=i_{\mathrm{q} \text { ref }}, \text { for any motor acceleration } .
$$

Furthermore, usual errors on the measurement of $\Omega$ are offset and gain errors :

$$
\Omega_{\mathrm{m}}=(1+\lambda) \Omega+\Omega_{0}
$$

where $\Omega_{0}$ represents the offset error, and $\lambda$ represents the gain error $(\lambda \ll 1)$. Anyway, we have :

$$
\Omega-\Omega_{\mathrm{m}}=-\lambda \Omega-\Omega_{0} .
$$


Thus :

$$
\sigma=\frac{\mathrm{d}}{\mathrm{d} t}\left(\Omega-\Omega_{\mathrm{m}}\right)=-\lambda \frac{\mathrm{d} \Omega}{\mathrm{d} t}=-\lambda \gamma
$$

We have then :

$$
|\sigma| \ll|\gamma| .
$$

The role of $\sigma$ in the expression of the steady states $i_{\mathrm{d} \infty}$ and $i_{\mathrm{q} \infty}$ obtained by the use of the total compensation controller with integrators, is similar to the role of $\gamma$ for the P.I. controller in the $D-Q$ frame. Thus, we deduce from the last consideration that the influence of the dynamics of $\Omega$ on the torque regulation is highly attenuated, by the use of a total compensation controller with integrators, even with an imprecise measurement of the speed $\Omega_{\mathrm{m}}$.

4.4 IMPLEMENTATion. - We made an experimental comparison between a classical proportional integral controller in the $\mathrm{D}-\mathrm{Q}$ frame, and our total compensation controller with integrators. The PWM period is $100 \mu \mathrm{s}$, while the sampling period is $600 \mu \mathrm{s}$ (calculation time is about $500 \mu \mathrm{s}$ for our microprocessor Intel 8086). The experimental implementation of these algorithms gives the results shown in figure 10 . We see on this figure the response of each of these two controllers, for a step experiment on $i_{\mathrm{qref}}$. The motor is not loaded, and consequently the speed evolves with great dynamics (see Fig. 4). We can see, in figure 10, that the static error on $i_{\mathrm{d}}$ and $i_{\mathrm{q}}$, coming from this high dynamics on $\Omega$, is considerably reduced by the use of the total compensation controller with integrators $(3.8 \mathrm{~A}$ static error for the P.I. controller, $1.8 \mathrm{~A}$ for the total compensation controller with integrators).

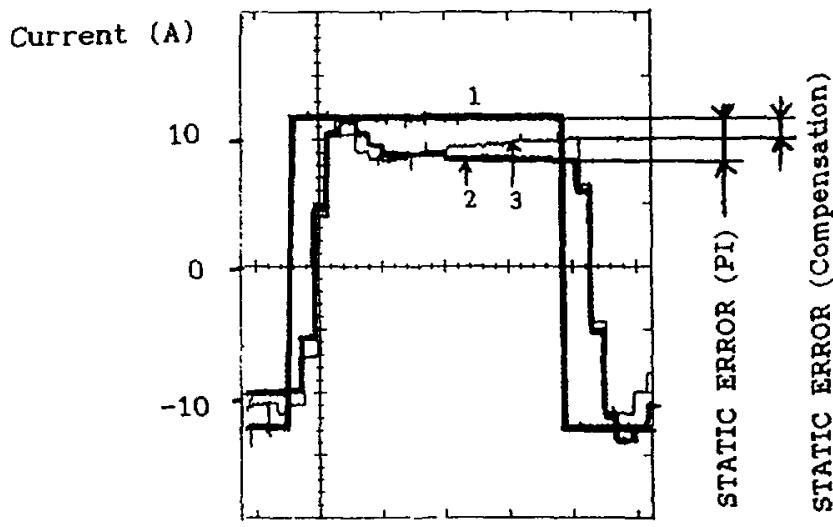

1: I 2: $\mathrm{i}$ (PI carrector, DQ referential) 3: $i_{q}^{q}$ (Compensation corrector).

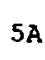

$5 A$

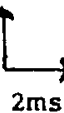

$\frac{\mathrm{d} \Omega}{\mathrm{dt}}=3900 \mathrm{Rd} / \mathrm{s}^{2}$

Fig. 10. - Experimental comparison between: the P.I. controller in the D-Q frame; the total compensation controller whith integrators. Step experiments on $i_{\mathrm{q}}$. Implementations. Influence of $\gamma$.

\section{Conclusion.}

The total compensation controller with integrators is an efficient alternative to the classical proportional integral controller in the D-Q frame. This controller takes care of the couplings in the model, and also compensates the induced electromotive voltages. We also realized that 
the robustness of this controller against an error on the measurement of the speed $\Omega$ is very convincing, because of its integrators.

Moreover, we obtain with such a method quite efficient results, with an implementation which is rather simple, and a calculation time of the microprocessor which is not prohibitive.

Nevertheless, this controller does not take into account the non-linearities of our model (see the state equations). If we want not to neglect these non-linearities we must use a non linear control. We also study such controls [10-12].

Another way to improve our method is to use an algorithm which takes into account the sampling and the calculation time, in order to minimize their effects. For this point, we study controllers which allow us to predict the state value, one (or several) sampling period steps ahead, and sampled-data control schemes more efficient than the usual zero-order-holder.

\section{Acknowledgment.}

We thank D. Normand-Cyrot and S. Monaco for their contribution to this study.

\section{Appendix.}

\section{Motor characteristics :}

Nominal current $I=20 \mathrm{~A}$, Nominal speed $=2200 \mathrm{round} / \mathrm{min}=230 \mathrm{rd} / \mathrm{s}$

Maximum transient current $I_{\max }=30 \mathrm{~A}$

Maximum transient torque $=14 \mathrm{NM}$

Maximum stationary torque for the motor stopped $=10 \mathrm{NM}$

Maximum torque at $2200 \mathrm{round} / \mathrm{min}=C_{\text {nom }}=8.5 \mathrm{NM}$

$$
R=0.6 \Omega, L_{\mathrm{d}}=1.4 .10^{-3} \mathrm{H}, L_{\mathrm{q}}=2.8 .10^{-3} \mathrm{H}, p=4, \Phi_{\mathrm{f}}=0.12 \mathrm{~Wb}
$$

Gain of current sensors $k_{1}=\frac{256}{50}$

Inverter continuous voltage $E=150 \mathrm{~V}$

Maximum acceptable acceleration (motor unloaded) :

$$
\left[\frac{\mathrm{d} \Omega}{\mathrm{d} t}\right]_{\max }=C_{\mathrm{nom}} / \mathrm{J}=7720 \mathrm{rd} / \mathrm{s}^{2}
$$

\section{References}

[1] Binet M., Thibaut P., Variateur à Transistor pour Moteur Autosynchrone, Electronique de Puissance (February 1984) pp. 43-47.

[2] BOSE B. K., Technology trends in microcomputer control of electrical machines, IEEE Trans. Ind. Electron. 35 (February 1988) $\mathrm{N}^{\circ} 1$.

[3] PIllay P., KRISHNAN R., Modeling, simulation, and analysis of permanent-magnet motor drives, part 1: the permanent-magnet synchronous motor drive, IEEE Trans. Ind. Appl. 25 (March/April 1989) $\mathrm{N}^{\circ} 2$.

[4] Lajoie-Mazenc M., Villanueva C., Hector J., Study and implementation of hysteresis controlled inverter on a permanent magnet synchronous machine, IEEE Transac. on Industr. Appl. IA-21 (March/April 1985) $\mathrm{N}^{\circ} 2$.

[5] BlaschKe F., Das Prinzip der Feldorientierung, die Grundlage für die Transvector-Regelung von Asynchronmaschinen, Siemens-Z. 45 (1971) 757.

[6] Grotstollen M., Pfaff G., Bürstenloser Drehstrom-Servoantrieb mit Erregung durch Dauermagnete, ETZ Bd. 100 (1979) 1382. 
[7] LeONHARD W., Control of electrical drives (Springer-Verlag, 1985).

[8] Louis J. P., LE PIOUfLE B., Représentation fonctionnelle des machines à courant alternatif et de leur alimentation pour leur commande en vitesse variable, Journées S.E.E. « Les actionneurs électriques, esclaves des temps modernes », pp. 13/1-13/27 (Valence, France) November 1989.

[9] Bergmann C., Goureau P., Louis J. P., Direct Digital Control of a Self-Controlled Synchronous Motor with Permanent Magnet, First European Conf. on Power Electronics and Applications, EPE (Brussels, Belgium) October 1985.

[10] Le Pioufle B., Georgiou G., Louis J. P., Application des commandes non linéaires pour la régulation en vitesse ou en position de la machine synchrone autopilotée, Revue Phys. Appl. 25 (1990) 517-526.

[11] Le Pioufle B., Georgiou G., Louis J. P., Bergmann C., Application of a decoupling controller and nonlinear methods for the control of selfcontrolled synchronous motors, Nancy, France IMACS-TC1'90, 2 (September 1990) pp. 527-532.

[12] GeORgIOU G., LE PIOUfLE B., Nonlinear speed control of a synchronous servomotor with robustness EPE, Florence (September 1991).

[13] IsidoRi A., Nonlinear Control Systems, an Introduction 2nd Ed. (Springer-Verlag, 1989).

[14] De LuCas A., Ulivi G., Full linearization of induction motors, nonlinear state feedback Proc. of the 26th conference on decision and control (1984).

[15] De larminat P., Thomas Y., Automatique des systèmes linéaires tome 3 (Flamarion Sciences, 1977).

[16] Ghribi M., Dube Y., Al HAdDAD K., Linear quadratic control of a DC drive EPE AACHEN (1989) pp. 261-265.

[17] Bergmann C., Présentation de différentes régulations numériques de courant par la méthode de l'échantillonneur équivalent, J. Phys. III France 1 (1991) 349. 